\title{
Языковая идентичность фольксдойче в оккупированных Польше, Белоруссии и на Украине
}

\section{Językowa tożsamość volksdeutschy w okupowanych Polsce, na Białorusi i Ukrainie}

Volksdeutsche, czyli Niemcy mieszkający poza Rzeszą, zajmowali kluczowe miejsce w planach narodowosocjalistycznych przywódców w zakresie organizacji zarządzania okupowanymi obszarami na Wschodzie. Stanowili oni główną ludzką rezerwę dla germanizacji Polski i niektórych obszarów ZSRR. Podstawowym zadaniem władz III Rzeszy było uczynienie z wielokulturowego i wielojęzycznego kontyngentu volksdeutschów jednolitej językowo i ideologicznie ludzkiej masy spełniającej standardy właściwe ludności "starej” Rzeszy. Poziom znajomości języka niemieckiego odegrał ważną rolę w określeniu statusu volksdeutschy w nowej sytuacji społecznej, a ich dwujęzyczność uczyniła z nich ważne ogniwo w pośrednictwie między władzami okupacyjnymi a lokalną ludnością na okupowanych terenach.

Słowa kluczowe: polityka językowa, okupacja, volksdeutsche, Trzecia Rzesza

Среди литературы о фольксдойче совсем немного источников, посвященных языковой проблематике немцев, живших на оккупированных территориях во время Второй мировой войны. Как известно, определение «немцы» в отношении фольксдойче несколько 
условно. Этим термином мог обозначаться широкий круг лиц, имеющих какое-либо отношение к немецкому населению вне границ рейха: от собственно немцев, очутившихся за пределами Германии после Первой мировой войны, до потомков «екатерининских» немцев, потерявших связь с исторической родиной еще в XVIII веке; от немцев, сохранивших свой язык в качестве родного, до таких, которые не знали ни слова по-немецки. В статье мы попытаемся показать, как работа новых властей по языковой адаптации фольксдойче на территории оккупированных Польши, Украины и Белоруссии представлена в прессе и документах того времени, а также в научных исследованиях, посвященных периоду оккупации.

Философия стратификации населения по национальному признаку, характерная для национал-социалистической идеологии, применялась оккупационными властями и для немцев вне рейха. Как известно, внутри этой группы было выделено четыре категории фольксдойче, находившихся между собой в иерархических отношениях: от самой «ценной» первой категории (собственно фольксдойче - активисты немецкого движения за границами рейха) до «проблемной» четвертой (т. н. Rückgedeutsche - ассимилированные немцы, представители властей своих стран).

Кроме критерия политической активности, важную роль в отнесении к той или иной категории фольксдойче играл немецкий язык. Так, для первой категории (собственно фольксдойче) знание немецкого языка подразумевалось само собой. Ко второй категории (т. н. лица немецкого происхождения, Deutschstämmige) относились политически пассивные немецкоязычные граждане Польши (позднее и других стран), т. е. наряду с национальностью главным критерием было владение немецким языком. Следующая, третья категория фольксдойче предполагала незнание немецкого языка: к ней относилось ассимилированное население немецкого происхождения (в т. ч. кашубы, силезцы и мазуры), а также способные к онемечиванию члены семей первых двух категорий фольксдойче, не принадлежавшие к этническим немцам. В эту 
группу допускались и «группы населения со славянским языком общения в семейном кругу» ${ }^{1}$. И, наконец, четвертая, низшая ступень среди фольксдойче - это «полукровки», имеющие хотя бы одного родителя-немца, полностью или частично ассимилированные «чуждыми» народами, или немцы, активно работавшие во враждебных Германии организациях. Их предполагалось «вернуть в лоно немецкости» через перевоспитание: привить идеологию национал-социализма, а также вернуть немецкий язык и культуру. Как видно, немецкий язык по понятным причинам был одной из ключевых составляющих в системе расовых ценностей, в политике по отношению к немцам зарубежья, претендующим на «расовую полноценность».

Однако не следует преувеличивать важность владения немецким языком в идеологии национал-социализма. Первоочередную и принципиальную роль для отнесения к фольксдойче играло происхождение, «немецкая кровь». Даже человек прекрасно владеющий немецким языком, активно проявивший себя в национальном движении не мог претендовать на статус фольксдойче. Такое отношение к языку восходит к доктрине германизации Гитлера. По его мнению, германизация не связана напрямую с языком и невозможна через освоение немецкого языка другими народами: «германизация может быть осуществлена только на некоторой территории, но не с народом, не с людьми», а «преодоление отчетливых ранее границ между разными народами и, наконец, их стирание из-за единого языка $[. .$.$] означает [. .$.$] уничтожение германского$ элемента» ${ }^{2}$.

По Гитлеру, национальный характер связан не столько с языком, сколько находится «в крови» народа. И если народ-завоеватель смешивается с завоеванным народом, то при этом он теряет «культур-

${ }^{1}$ I. Fleischhauer, Das Dritte Reich und die Deutschen in der Sowjetunion, München 1983, s. 70.

${ }^{2}$ A. Hitler, Mein Kampf, München 1936, s. 428. 
ные силы», пусть даже полученный «смешанный» продукт-народ «тысячу раз говорит на языке бывшей высшей расы»

Языковая политика по отношению к населению немецкого происхождения на оккупированной территории, проводимая на местах новыми властями, нашла свое отражение в прессе и документах 1939-1945 годов, которые сохранились в архивах Польши, Беларуси, Германии и ряда других стран, а также в немецкой прессе того времени.

\section{Фольксдойче на территориях Польши, включенных в рейх}

Как известно, часть оккупированной польской территории была аннексирована, включена на правах административных единиц в состав рейха: т. н. Вартеланд (Wartheland), Данциг - Западная Пруссия (Danzig - Westpreußen) и Восточная Пруссия вместе с Белостокским округом (Ostpreußen u. Bezirk Bialystok).

Так как аннексированные территории Польши должны были соответствовать общенемецким стандартам, в том числе и в области языковой политики, то особые надежды новые власти возлагали на переселенных в западную Польшу фольксдойче, которые должны были хоть в какой-то мере изменить состав населения в пользу «германского элемента». Из примерно полумиллиона немецкоязычных граждан СССР около 100 тысяч очутились в зоне оккупации вермахта и гражданской администрации. Многие из них были переселены в западную Польшу, в новую провинцию рейха - Вартеланд 4 Кроме «советских» немцев, сюда могли попасть и «словацкие» фольксдойче Прикарпатской Руси, более половины которых (около 8000 человек) уехали после аннексии этой территории Венгрией.

${ }^{3}$ Ibidem, s. 429.

${ }^{4}$ D. Scholten, Sprachverbreitungspolitik des nationalsozialistischen Deutschlands, Frankfurt am Main, Wien [u. a.] 2000, s. 291. 
Многих из этих фольксдойче-переселенцев предстояло ассимилировать как в языковом, так и в идеологическо-культурном плане 5 .

В письме от 29 апреля 1941 года рейхсминистра по науке, воспитанию и народному образованию по поводу школьного образования для детей-фольксдойче, переселившихся в рейх из Волыни, Бессарабии и других восточных областей, отмечается, что большая часть этих детей «немецким языком не владеет вообще или владеет им только в недостаточной степени в рамках школьной программы. Неотложный национальный интерес состоит в том, чтобы детям этих переселенцев, которые останутся в рейхе, обеспечить регулярные школьные занятия по основам чтения и письма, и тем самым использовать то время, пока они находятся во временном лагере ${ }^{6}$. Это письмо предназначалось для всех новых территорий рейха, в которых предполагалось расселить прибывших из бывших советских территорий фольксдойче: среди адресатов этого письма - школьные службы и руководители Судетской области, региона Данциг - Западная Пруссия, Саарпфальца, Вартеланда, Пруссии, т. е. тех оккупированных областей, куда переселяли восточных фольксдойче. Система мер по возвращению фольксдойче в сферу немецкой цивилизации получила особое название в языке немецкой номенклатуры - Rückdeutschungsarbeit («работа по возвращению немецкости»).

Даже в январе 1945 года языковая проблема у части молодых фольксдойче не была решена. В служебном письме от 10 января 1945 года был представлен план работы «по возвращению немецкого духа среди молодежи в 1945 г.» в Вартеланде. Одна из сотрудниц оккупационной администрации Марго Фроверк (Margot Frohwerk) предлагает устроить лагеря для подростков 10-14 лет и разделить их на две группы: «парней и девушек, которые по [немецкому. - A. 3.] языку так плохи, что должны быть повторно на-

\footnotetext{
${ }^{5}$ Ibidem.

${ }^{6}$ G. Hansen, Schulpolitik als Volkstumspolitik, Münster, New York 1994, s. 29.
} 
правлены в летний лагерь для повторения», и тех, кто «может быть приравнен к нашим юношам и девушкам или как минимум в этой среде может быстро дорасти до их уровня» ${ }^{7}$

Были ли предусмотрены меры воздействия на тех фольксдойче, кто не прикладывает достаточно усилий в овладении немецким языком? В этой связи заслуживает внимания письмо отделения Национал-социалистической немецкой рабочей партии в Вартеланде, разосланное в середине 1943 года всем окружным руководителям и посвященное языковому обучению взрослых. В нем говорится о применении принудительных мер в случае злостного неучастия в мероприятиях по языковому обучению. Приведу выдержки из письма, в котором оговариваются штрафные меры при нежелании фольксдойче изучать немецкий язык: «Круг лиц, которым необходимо языковое обучение, был определен окружной администрацией по вопросам национальностей... Как я уже упоминал в своей записке от 20.5.43 г., изучение [немецкого. - A. 3.] языка должно принципиально строиться на добровольной основе. Воспитание всех немцев, живущих в округе, в духе безукоризненного владения немецким языком [...] это срочное дело, которое в рамках нашей воспитательной работы должно быть привито немецкому народу всеми [здесь и далее выделено в документе. - $A$. 3.] имеющимися средствами. Для этого в случае, если языковое обучение не может проводиться на основе добровольности, могут применяться также принудительные меры. Я приказываю настоящим, чтобы в случае злостного неучастия в мероприятиях по языковому обучению применялись следующие принудительные меры:

1. Лицам, принадлежащим к пункту 3 фолькслисте [Deutsche Volksliste, см. выше. - A. 3.], может быть отказано в немецком гражданстве.

2. У лиц, принадлежащих к пункту 3 фолькслисте, изымается удостоверение принадлежности к фолькслисте.

${ }^{7}$ Ibidem, s. 62-63. 
3. Фольксдойче-переселенцев возвращать в их прежние места пребывания» ${ }^{8}$.

Как видно, меры, призванные обеспечить изучение и употребление немецкого языка в округе Вартеланд, предельно строги. Далее, правда, следуют оговорки, что применение этих мер осуществляется не автоматически, а по решению уполномоченных комиссий в каждом конкретном случае, особенно в случае с фольксдойче-переселенцами: рассматривается поведение человека и его семьи в целом и лишь затем решается, подходит ли человек для проживания в восточной части рейха.

Кроме работы по языковой регерманизации фольксдойче, можно отметить и другую сторону языковой проблематики. Не позднее 1943 года встал вопрос о преподавании славянских языков, прежде всего русского и украинского, в школах рейха. Предполагалось, что это поможет подготовить квалифицированный персонал для работы на оккупированных восточных территориях. 19 апреля 1943 года рейхсминистр по науке, воспитанию и народному образованию послал руководству Вартеланда письмо касательно введения занятий по украинскому и русскому языкам в школах рейха: «Развитие экономики, техники и административного аппарата на оккупированных восточных территориях все в большем объеме требует привлечения сотрудников, владеющих украинским или русским языком. [...] Так как украинский и русский языки в особенно важных для подобной миссии средних учебных заведениях и учительских школах вообще не преподавались, [...] я позволю себе проявить инициативу введения украинского и русского языков в некоторых школах рейха. [...] В качестве учителей указанных языков для начала могут привлекаться фольксдойче с соответствующим языковым образованием, для которых предлагается организовать курсы по методике преподавания. [...] Для работы на востоке учащиеся в начальной и сред-

${ }^{8}$ Ibidem, s. 81-83. 
ней школе должны заниматься русским или украинским языком от трех до пяти часов в неделю» ${ }^{9}$.

На это письмо в июне 1943 года был получен ответ из канцелярии в Познани о невозможности осуществления в настоящий момент указаний по введению в школьную программу вышеупомянутых славянских языков из-за отсутствия учителей данного профиля или их занятости в преподавании актуальных обязательных дисциплин ${ }^{10}$.

Однако уже через девять месяцев, в марте 1944 года, проблема с немецким языком и некоторыми страноведческими дисциплинами по германистике у детей 160 тысяч переселенцев фольксдойче из черноморского региона заставила школьное руководство Вартеланда через канцелярию руководителя области направить письмо рейхсминистру по науке, воспитанию и народному образованию с просьбой о замене в Лицманштадте [Лодзь. - A. 3.] занятий по английскому языку на занятия по русскому языку, который был первым или вторым родным языком для большинства черноморских фольксдойче ${ }^{11}$. Эта замена была необходима для того, чтобы высвободить учебное время для дополнительного изучения немецкого языка и германистических дисциплин. В ответе, полученном через месяц, предлагалось в первых и вторых классах вообще отказаться от иностранных языков в пользу немецкого языка, а в третьем классе изучать иностранные языки по имеющейся учебной программе; учащимся старших классов было разрешено изучать русский вместо английского языка ${ }^{12}$.

Еще одной сферой деятельности для учителей-фольксдойче были польские школы с немецким языком обучения. На территориях Польши, включенных в рейх, оккупационными властями как

\footnotetext{
${ }^{9}$ Ibidem, s. 99-101.

${ }^{10}$ Ibidem, s. 101-102.

${ }^{11}$ Ibidem, s. 102-103.

${ }^{12}$ Ibidem, s. 103.
} 
минимум до середины 1942 года не было организовано для польских детей ни одной школы с польским языком обучения. В лучшем случае они могли посещать школы для поляков с немецким языком обучения, которые предусматривали изучение только основ немецкого языка и арифметики. При этом польских учителей для таких школ нанимать запрещалось - там работали исключительно фольксдойче без образования ${ }^{13}$.

И, наконец, следует упомянуть языковое посредничество фольксдойче между армией, оккупационными властями и местным населением. Благодаря знанию русского, украинского и других языков бывшего СССР фольксдойче активно привлекались на работу в структуры почтовой цензуры. Там их полем деятельности была проверка входящей и исходящей корреспонденции семей фольксдойче, в которых были мобилизованные в армию или на работу в рейх ${ }^{14}$. Примером массового привлечения фольксдойче к работе переводчиков является отправка в 1942 году 580 девушек-переводчиц фольксдойче со знанием украинского и русского языков в структуры самолетостроения. После «чрезвычайно хорошего опыта работы с ними» ${ }^{15}$ Министерством воздушного сообщения рейха в начале 1943 года был поставлен вопрос о направлении еще 1000 переводчиц в распоряжение этого министерства.

Билингвизм (или даже мультилингвизм) фольксдойче, которые нередко знали наряду с немецким русский, польский, украинский и другие языки, хорошо вписывался в расовый подход в области языковой политики, согласно которому было нежелательно или просто запрещено преподавать немецкий язык местному славянскому населению, чтобы избежать в последующем его онемечивания и тем самым «порчи немецкой крови» ${ }^{16}$. Поэтому использова-

${ }^{13}$ Ibidem, s. 226-227.

${ }^{14}$ I. Fleischhauer, op. cit., s. 136-137.

${ }^{15}$ Ibidem.

${ }^{16} \mathrm{O}$ запретах в области изучения немецкого языка польским населением в Вартеланде см. директиву по языковому вопросу руководителя Вартеланда от 
ние би- или мультилингвальных фольксдойче в административной работе позволяло организовать коммуникацию с местным населением.

\section{Языковая политика в отношении фольксдойче в Генерал-губернаторстве}

Больших различий в отношении языкового образования фольксдойче между аннексированными районами Польши и Генерал-губернаторством не было: там также проводилась интенсивная языковая ассимиляция фольксдойче. Например, на этих территориях организовывались вечерние школы для взрослых фольксдойче. Как видно из внутренней переписки оккупационных властей округа Радомско в Генерал-губернаторстве (письмо от 24 октября 1941 года), на курсах преподавались немецкий язык, история, национал-социалистическая идеология, немецкие песни. Занятия проводились вечером, преимущественно в зимние месяцы в помещениях немецких школ. Кроме того, существовали и обязательные профессиональные школы для молодежи фольксдойче 14-17 лет, в которых в основном преподавался немецкий язык ${ }^{17}$.

Нередко не только школьники-фольксдойче, но и их учителя из среды немцев-переселенцев не обладали общим с немцами из рейха информационным контекстом, который казался партийным функционерам рейха само собой разумеющимся общенемецким дискурсом. Например, вот выдержка из письма руководителя округа Радом от 6 июня 1940 года: «при проверке немецкой школы ни ученики старших классов, ни учитель, ни руководитель школы не были в состоянии сказать хотя бы одно-единственное слово

23 февраля 1943 года: G. Hansen, op. cit., s. 84. В отношении Украины см. письмо А. Розенберга в Рейхскомиссариат «Украина» от 13 января 1942 года: Нацыянальны архіў Рэспублікі Беларусь (НАРБ), ф. 652, спр. 1, воп. 1, арк. 88-89.

${ }^{17}$ G. Hansen, op. cit., s. 87. 
о значении Первого мая. А часть школьников не смогла сказать, как зовут фюрера. [...] Подобное незнание у учителя-фольксдойче, по моему мнению, недопустимо и ставит его способность преподавать в немецкой школе под вопрос» ${ }^{18}$.

На языковую проблему фольксдойче в Генерал-губернаторстве часто обращала внимание и оккупационная пресса. Так, в статье об организации курсов для фольксдойче-руководителей хоров, опубликованной в конце 1942 года в Кракове, красной нитью проходит мысль о лучшей социализации фольксдойче через традиционную немецкую культурную жизнь и отмечается языковая пестрота немцев, переселившихся в Генерал-губернаторство: «От говорения - к певчему оркестру (курсы для фольксдойче-руководителей хорового пения). Здесь, в Генерал-губернаторстве, куда приехало множество [немецких. - A. 3.] переселенцев из дальних восточных территорий, вы найдете в основном людей, которые редко в полной мере владеют немецким родным языком, а говорят с ярко выраженным акцентом, обусловленным областью их происхождения» ${ }^{19}$.

В сентябре 1943 года газета „Krakauer Zeitung“ в статье «Любовь к Родине через родной язык» писала о курсах языкового воспитания в Закопане, которые устраивались начальником главного отдела науки и образования Генерал-губернаторства доктором Айххольц (Eichholz) для директоров и учителей школ из всех округов Генерал-губернаторства: «Язык - высшая ценность народа. Именно поэтому воспитание на родном языке является самой главной задачей школы. [...] Занятия по немецкому языку ставят перед учителями немецкого языка совсем новые задачи. Многие дети в наших немецких школах в Генерал-губернаторстве являются выходцами из польского языкового мира, они должны сначала войти в мир немецкого языка. Этот язык должен быть естественным для них,

\footnotetext{
${ }^{18}$ Ibidem, s. 95.

${ }^{19}$ Vom Sprechen bis zum Sing-Orchester, „Krakauer Zeitung” 1943, 1 декабря.
} 
чтобы при общении на нем была видна их душа. Другие дети постоянно говорят на немецком языке в семье, но у них „твердое” немецкое произношение, характерное для восточной смешанной языковой области. Все эти особенности требуют от учителей немецкого языка применения особых методик проведения занятий, которые и стоят в центре внимания на упомянутых выше курсах» ${ }^{20}$.

Не следует забывать, что у руководителей рейха после оккупации новых территорий бывшего СССР появилась и крепла идея онемечить со временем и Генерал-губернаторство, отказавшись от первоначальной идеи создания здесь своего рода резервации для поляков и нежелательных элементов из рейха. Поэтому при разработке т. н. генерального плана «Ост» в Генерал-губернаторстве предусматривалось на первом этапе германизации этой территории создать большое количество колоний-поселений фольксдойче ${ }^{21}$.

В 1942-1943 годах в Генерал-губернаторстве можно отметить тенденцию к открытию не просто школ для фольксдойче, а закрытых школ-интернатов для местных немцев. Вот как обосновывала необходимость создания таких учебных заведений „Krakauer Zeitung": «В процессе полонизации необходимо пробить брешь, нужно остановить его и сделать неэффективным. Это может произойти только тогда, когда [немецкие. - A. 3.] дети будут избавлены от польского влияния и помещены в чисто немецкие условия. [...] Да, дети могут сейчас беспрепятственно посещать немецкие школы, [...] но при этом они не могут быть полностью избавлены от чуждого влияния, потому что после занятий $[\ldots]$ немецкие и польские дети играют вместе, и т. к. немецкие дети ранее изучали польский язык, он становится средством общения при этих совместных играх. Немецкий язык, который дети учили и на котором разговаривали до обеда в школе, уже не преобладает и остается в той или иной степени иностранным языком. Именно поэ-

\footnotetext{
${ }^{20}$ Vaterlandsliebe durch Muttersprache, „Krakauer Zeitung“ 1943, 14 сентября.

${ }^{21}$ Ю. Туронак, Беларусь пад нямецкай акупацьыяй, Мінск 1993, с. 106.
} 
тому [немецкие. $-A$. 3.] дети должны быть полностью изъяты из польского окружения» ${ }^{22}$.

В оккупационной прессе того времени можно найти и некоторые цифры относительно того, сколько детей фольксдойче училось на немецком языке в том или ином регионе. Так, к концу 1943 года в Варшаве, по данным „Krakauer Zeitung“, проживало около 2000 детей школьного возраста ${ }^{23}$, а в Варшавском районе (Distrikt Warschau) к ноябрю 1943 года в 40 немецких школах обучались 4500 учеников ${ }^{24}$. Издание „Ost-Express“ указывало, что в Генерал-губернаторстве в целом к февралю 1942 года было организовано 210 школ с 350 классами, количество посещающих эти школы детей составляло более 12000 человек, а учителей - 38025. В Радомском районе (Distrikt Radom), где находились большие поселения фольксдойче, уже к февралю 1942 года насчитывалось более 100 немецких школ ${ }^{26}$. Первая немецкая школа в Кракове была открыта в середине января 1940 года; в нее были записаны 135 детей в возрасте от 6 до 19 лет, а через год уже работало четыре школы с 600 учащимися ${ }^{27}$.

\section{Фольксдойче в Рейхскомиссариате «Остланд» и на Украине}

В апреле 1942 года Министерство по делам восточных оккупированных территорий выпустило документ под названием «Основные положения по обращению с фольксдойче», предназначенный в основном для военных властей в оккупированных советских областях. Общая линия этого указа состоит во всесторонней под-

${ }^{22}$ Schulen als Heimstätten der Jugend, „Krakauer Zeitung“ 1943, 18 апреля.

${ }^{23}$ Festigung des Deutschtums in der Jugend, „Krakauer Zeitung“ 1943, 17 декабря.

${ }^{24}$ Deutsche Schulen für deutsche Kinder, „Krakauer Zeitung“ 1943, 30 октября.

${ }^{25}$ Die deutsche Schulen im Generalgouvernement, „Ost-Express“ 1942, 14 февраля.

${ }^{26}$ Förderung des deutschen Schulwesens im Generalgouvernement, „Ost-Express“ 1942, 6 февраля.

${ }^{27}$ Vier deutsche Schulen in Krakau, „Kattowitzer Zeitung“ 1941, 22 января. 
держке местного немецкого населения оккупационными властями и помощи в возвращении фольксдойче в лоно немецкой культуры через оживление социальных контактов внутри немецкой диаспоры и поддержку немецкого языка ${ }^{28}$.

Не позже октября 1942 года в Министерстве по делам восточных оккупированных территорий был готов и уже претворялся в жизнь план школьного образования для фольксдойче, живущих в Рейхскомиссариате «Остланд». В годовом отчете группы школьной политики (отдел воспитания и образования) ${ }^{29}$ от 28 октября 1942 года отмечалось: «Основные направления школьного образования для немцев и фольксдойче определены. Проект школьного образования для местного населения находится еще у господина рейхсминистра. [...] На Украине сейчас работают около 1000 фольксдойче учителей и 25 чиновников по надзору за школами. В ближайшие дни будут организованы первые курсы для учителей в Киеве. В Остланде для немецких детей организованы школы, в том числе высшие школы в Риге и Таллинне. Другие высшие школы будут организованы в Каунасе и Вильнюсе ${ }^{30}$.

Информация о фольксдойче в Генеральном комиссариате «Белоруссия» (Generalkommissariat Weissruthenien) достаточно скупа, в основном это статьи в газетах того времени, где говорится об открытии школ для немецких детей. Например, в начале 1942/1943 учебного года газета „Minsker Zeitung“ опубликовала небольшую заметку об открытии пяти школ для фольксдойче в Минской области: «Благодаря инициативе окружного комиссара Минской области были организованы школы для детей фольксдойче в Смолевичах, в Малом Залужье, Дроздах и Жодино. В воскресенье торжественно откроется пятая школа для фольксдойче - в Зазерье» ${ }^{31}$.

${ }^{28}$ I. Fleischhauer, op. cit., s. 159-160.

29 Документ подписан Оскаром Кинцленом (Oskar Kienzlen), занимавшимся в 1941-1943 годах восстановлением школьного образования в Остланде.

${ }^{30}$ НАРБ, ф. 652, воп. 1, спр. 1, арк. 262-263.

${ }^{31}$ Volksdeutsche Schule in Sasserge, „Minsker Zeitung“ 1942, 15 сентября. 
Более подробно о происхождении и количестве фольксдойче в Жодино эта газета писала чуть ранее: «В Жодино (Минский округ) вчера была открыта четвертая школа для детей фольксдойче. В Жодино живут 24 семьи (волжские немцы), которые сейчас могут отправить своих 28 детей школьного возраста в школу с учителем-фольксдойче» ${ }^{32}$.

Пятью месяцами ранее в газете „Deutsche Zeitung für Ostland“33 было опубликовано небольшое сообщение об открытии в Дроздах под Минском школы для 26 детей фольксдойче, третьей по счету в Минском районе. Там говорилось о «большом числе фольксдойче и волжских немцев» (zahlreiche Volks- und Wolgadeutsche), живущих в Генеральном комиссариате «Белоруссия».

Откуда появились фольксдойче в Белоруссии, проясняет пассаж из статьи «Свежий ветер из Белоруссии» об открытии Вильгельмом Кубе первой школы для немцев в Белоруссии - в Смолевичах, в 50 км восточнее Минска: «Эти потомки немцев из Саксонии и Рейнланд-Пфальца, приехавшие 200 лет назад в Россию, [...] бежали сюда с Волги после начала коллективизации, которая угрожала их жизни и всему нажитому имуществу. Они и их дети [...] говорят и думают по-немецки» ${ }^{34}$.

В статье говорится, что волжские немцы появились в Белоруссии в первые годы коллективизации, когда бежали от экспроприации собственности из своего традиционного места проживания на Волге.

Судя по всему, белорусские фольксдойче не играли существенной роли в планах берлинских оккупационных властей. Возможно, из-за того, что организация немецких поселений-колоний на территории Белоруссии не предполагалась. Ю. Туронок говорит о том,

${ }^{32}$ Neu volksdeutsche Schule eingeweiht, „Minsker Zeitung“ 1942, 4 сентября.

${ }^{33}$ Deutsche Schulen in Weissruthenien, „Deutsche Zeitung für Ostland“ 1942, 17 апреля.

${ }^{34}$ Frischer Wind aus Weissruthenien, „,Deutsche Zeitung für Ostland“ 1942, 7 марта. 
что в проекте генерального плана «Ост» (в его первом варианте) предусматривалось создание 36 немецких колониальных баз, в большой степени из фольксдойче: 14 - в Генерал-губернаторстве, 8 - на Украине и 14 - в Остланде ${ }^{35}$.

Сколько фольксдойче проживало на Украине к началу войны? Если опираться на немецкие источники военного времени, то в материалах для служебного пользования «Национальные отношения, paca, язык и поселения на Украине», опубликованных в 1942 году,

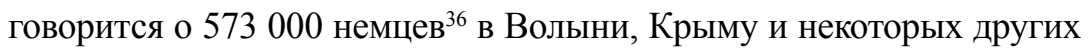
регионах ${ }^{37}$. Интересно, что подобное издание «Украина в цифрах», вышедшее в 1941 году, указывает цифру в 711000 фольксдойче, оговаривая, что эти данные взяты из советских довоенных источников ${ }^{38}$.

Одна из самых значительных колоний фольксдойче находилась на Волыни. На момент начала немецкой оккупации в 1941 году здесь проживало около 45000 фольксдойче ${ }^{39}$. В газете „Deutsche Ukraine-Zeitung“ в мае 1942 года была помещена статья о жизни немцев в окрестностях города Новоград-Волынский. Автор пишет о 10000 фольксдойче, проживающих к маю 1942 года в этом районе. В городе была открыта четырехклассная школа для фольксдойче - одна из самых больших немецких школ на Украине с 200 учащимися и учителями из числа фольксдойче, со своим общежитием и столовой для немецких детей из близлежащих деревень. Планировалось и открытие в Новограде-Волынском учительской школы, которая должна была обеспечивать учителями 37-38 немецких школ района. И далее: «Фольксдойче придают большое

${ }^{35}$ Ю. Туронак, op. cit., с. 106.

36 Эту цифру указывает и J. Mirtschuk (Hrsg.), Handbuch der Ukraine, Leipzig 1941, s. 96.

${ }^{37}$ J. Papritz, W. Kohte (Hrsg.), Nationalitätenverhältnisse, Rasse, Sprache und Siedlungswesen in der Ukraine, Berlin 1942, s. 26-27.

${ }^{38}$ Idem, Die Ukraine in Zahlen, Berlin 1941, s. 19.

39 Schicksaalskampf der Wolhyniendeutschen, „Deutsche Ost-Korrespondenz“ 1944, 15 апреля. 
значение и поддерживают организацию курсов немецкого языка для взрослых фольксдойче. [...] Шестнадцати-двадцатипятилетние, а особенно учителя до 30 лет востребованы в качестве деревенских старост, руководителей районов, секретарей, переводчиков и т. д. Они незаменимы на тех должностях, которые предполагают контакт с украинским населением» ${ }^{40}$.

Есть и другие свидетельства того, что часть украинских немцев удивительно хорошо сохранили свою национальную идентичность. Например, И. Фляйшхауэр приводит отчет танковой группы 1, действовавшей в сентябре 1941 года в районе Кривого Рога и Запорожья. Там было зарегистрировано около 50 поселений немцев с 50000 жителей, которые «удивительно хорошо сохранили свой язык и национальную идентичность» ${ }^{41}$. Также и в одном из отчетов айнзатцгруппы, столкнувшейся в Западной Украине осенью 1941 года с населением немецких поселений, подтверждается тот факт, что дети фольксдойче там «говорят по-немецки» ${ }^{42}$.

В оккупационной прессе вновь «открытые» поселения советских фольксдойче описывались нередко как неожиданное столкновение с архаичной культурой, почти как встреча с неизвестным племенем в джунглях. Так, в апреле 1942 года в „Deutsche UkraineZeitung“ вышла статья «Открыто новое немецкое поселение» с подзаголовком «Окружной комиссар во время своей поездки натолкнулся на 400-летнее немецкое поселение», где помимо прочего отмечалось: «Люди, несмотря на свою долгую изменчивую историю, сохранили в чистоте свою немецкую национальную идентичность [Deutschtum] в языке и обычаях» ${ }^{43}$.

${ }^{40}$ Ein volksdeutscher Mittelpunkt entsteht, „Deutsche Ukraine-Zeitung“ 1942, 28 мая. Автор статьи делает интересное наблюдение, определяя язык своей собеседницы, девочки фольксдойче, как «самый настоящий восточно-прусский диалект».

${ }^{41}$ I. Fleischhauer, op. cit., s. 92.

${ }^{42}$ Ibidem, s. 105.

${ }^{43}$ Deutsche Dorfsiedlung entdeckt, „Deutsche Ukraine-Zeitung“ 1942, 24 апреля. 
Но после того, как немецкие войска заняли большие города и начали действовать восточнее Днепра, картина изменилась: связь немцев, живущих здесь, с этнической родиной была очень условна, отмечалась сильная русификация немецкого населения, «знания немецкого языка и немецкого воспитания у молодого поколения почти нет» ${ }^{44}$. А ситуация в больших городах была еще хуже: по отчетам айнзатцгруппы $\mathrm{C}$, расквартированной в Киеве, немецкое самосознание у фольксдойче в городах «почти полностью исчезло. [...] По-немецки говорят только изредка. Большинство детей вообще не изучало немецкий язык. В индустриальном районе Донецкого бассейна, к тому же, значительная часть фольксдойче большевизирована» ${ }^{45}$.

Эта ситуация подтверждается и материалами немецкой прессы, где, несмотря на пропагандистский характер статьи о положении 5000 фольксдойче в оккупированном Киеве, отмечалось: «часть детей не понимала ни слова по-немецки. В некоторых классах немецкий язык не изучался вообще» ${ }^{46}$. Немногим лучше, судя по всему, была и ситуация со взрослыми киевскими фольксдойче: «Как только дети уходят [из школы. $-A$. 3.] домой, их сменяют взрослые. Это тоже фольксдойче, которые хотят улучшить свой [немецкий. - A. 3.] язык. Сотни немцев годами не произносили ни слова по-немецки и сейчас вернулись к источнику своей жизни, к языку, чтобы выразить свою сущность на родном языке» ${ }^{47}$.

Таким образом, можно сказать, что языковая политика Германии в отношении фольксдойче в оккупированной Польше, Белоруссии и на Украине предусматривала следующие задачи:

1. Языковая регерманизация тех фольксдойче, которые не владели в достаточной степени немецким языком или вообще не знали

\footnotetext{
${ }^{44}$ I. Fleischhauer, op. cit., s. 106.

${ }^{45}$ Ibidem.

${ }^{46}$ Die Suche nach 5000 Volksdeutschen, „Deutsche Ukraine-Zeitung“ 1942, 16 мая.

${ }^{47}$ Ibidem.
} 
его. Для этого во всех оккупированных регионах, где проживали фольксдойче, организовывались немецкие школы, летние лагеря, учительские курсы для фольксдойче и курсы немецкого языка для взрослых. Возврат зарубежных немцев в «лоно немецкости» находился под контролем оккупационных властей и при необходимости предусматривал принудительные меры против уклоняющихся от регерманизации.

2. Би- или мультилингвизм фольксдойче делал их незаменимыми языковыми посредниками между оккупационными властями и местным населением как в административной, так и в индустриальной сферах. Особенно это касалось не переселенных фольксдойче, а местных немцев. Кроме того, фольксдойче использовались для языкового контроля и цензуры населения, использующего не немецкий язык в кругу семьи.

3. В 1943-1944 годах фольксдойче начали активно использоваться не только в качестве учителей в немецких школах на оккупированных территориях, но и как преподаватели восточнославянских языков в школах «старого рейха» и в аннексированных районах Польши.

4. И, наконец, языковая компетенция двуязычных фольксдойче и их использование в качестве языковых посредников с местным населением отвечали расовой концепции национал-социализма о несмешивании народов, т. к. делала возможной коммуникацию с местным населением без необходимости преподавать ему немецкий язык.

\section{Архивные источники}

Нацыянальны архіў Рэспублікі Беларусь, ф. 652, воп.1, спр. 1, арк. 88-89, 262-263.

\section{Литература}

Deutsche Dorfsiedlung entdeckt, „Deutsche Ukraine-Zeitung“ 1942, 24 апреля. Deutsche Schulen für deutsche Kinder, „Krakauer Zeitung“ 1943, 30 октября. 
Deutsche Schulen in Weissruthenien, „Deutsche Zeitung für Ostland“ 1942, 17 апреля.

Die deutsche Schulen im Generalgouvernement, „Ost-Express“ 1942, 14 февраля.

Die Suche nach 5000 Volksdeutschen, „Deutsche Ukraine-Zeitung“ 1942, 16 мая. Ein volksdeutscher Mittelpunkt entsteht, „Deutsche Ukraine-Zeitung“ 1942, 28 мая. Festigung des Deutschtums in der Jugend, „Krakauer Zeitung“ 1943, 17 декабря. Fleischhauer I., Das Dritte Reich und die Deutschen in der Sowjetunion, München 1983.

Förderung des deutschen Schulwesens im Generalgouvernement, „Ost-Express“ 1942, 6 февраля.

Frischer Wind aus Weissruthenien, „Deutsche Zeitung für Ostland“1942, 7 марта. Hansen G., Schulpolitik als Volkstumspolitik, Münster, New York 1994.

Hitler A., Mein Kampf, München 1936.

Mirtschuk J. (Hrsg.), Handbuch der Ukraine, Leipzig 1941.

Neu volksdeutsche Schule eingeweiht, „Minsker Zeitung“ 1942, 4 сентября.

Papritz J., Kohte W. (Hrsg.), Die Ukraine in Zahlen, Berlin 1941.

Papritz J., Kohte W. (Hrsg.), Nationalitätenverhältnisse, Rasse, Sprache und Siedlungswesen in der Ukraine, Berlin 1942.

Schicksaalskampf der Wolhyniendeutschen, „Deutsche Ost-Korrespondenz“ 1944, 15 апреля.

Scholten D., Sprachverbreitungspolitik des nationalsozialistischen Deutschlands, Frankfurt am Main, Wien [u. a.] 2000.

Schulen als Heimstätten der Jugend, „Krakauer Zeitung“ 1943, 18 апреля.

Vaterlandsliebe durch Muttersprache, „Krakauer Zeitung“ 1943, 14 сентября.

Vier deutsche Schulen in Krakau, „Kattowitzer Zeitung“ 1941, 22 января.

Volksdeutsche Schule in Sasserge, „Minsker Zeitung“ 1942, 15 сентября.

Vom Sprechen bis zum Sing-Orchester, „Krakauer Zeitung“ 1943, 1 декабря.

Туронак Ю., Беларусь пад нямецкай акупацыяй, Мінск 1993.

\section{Language identity of the Volksdeutsche in occupied Poland, Belarus and Ukraine}

Volksdeutsche, i.e. Germans who lived outside the Reich occupied a key place in the plans of the Nazi leadership for the organization of the eastern occupied territories. They were the main human reserve for the Germanization of Poland and some areas of the USSR. The primary task for the German authorities was to bring the multicultural 
Андрей Зинкевич, Языковая идентичность фольксдойче...

and multilingual contingent of Volksdeutsche to the linguistic and ideological standards inherent in the population of the "old" Reich. The level of German language proficiency played an important role in determining the status of Volksdeutsche in the new social situation for them, and their bilingualism made them an important link in the mediation between the occupation authorities and the local population of the occupied territories.

Keywords: language policy, occupation, Volksdeutsche, Third Reich 